\title{
PARALLEL IMAGE PROCESSING
}




\section{SERIES IN MACHINE PERCEPTION AND ARTIFICIAL INTELLIGENCE}

Editors: H. Bunke (Univ. Bern, Switzerland) and

P. S. P. Wang (Northeastern Univ., USA)

Vol. 1: Pattern Recognition and Image Analysis: Selected Papers from the IVth Spanish Symposium (Eds. N. Pérez de la Blanca, A. Sanfeliu and E. Vidal)

Vol. 2: Theory and Applications of Image Analysis: Selected Papers from the 7th Scandinavian Conference on Image Analysis (Eds. P. Johansen and S. Olsen)

Vol. 3: Neural Networks in Vision and Pattern Recognition (Eds. J. Skrzypek and W. Karplus)

\section{Forthcoming}

Vol. 5: Advances in Structural and Syntactic Pattern Recognition: Proceedings of the International Workshop (Ed. H. Bunke) 
Series in Machine Perception and Artificial Intelligence - Vol. 4

\section{PARALLEL \\ IMAGE PROCESSING}

Edited by

A. Saoudi

Laboratoire d'Informatique Paris Nord

Université Paris XIII, Paris, France

M. Nivat

Laboratoire d'Informatique Théorique et Programmation

Université Paris VII, Paris, France

\section{P. S. P. Wang}

College of Computer Science, Northeastern University

Boston, Massachusetts, USA 


\section{Published by}

World Scientific Publishing Co. Pte. Ltd.

P O Box 128, Farrer Road, Singapore 9128

USA office: Suite 1B, 1060 Main Street, River Edge, NJ 07661

UK office: 73 Lynton Mead, Totteridge, London N20 8DH

\section{PARALlel IMAGE PROCESSING}

Copyright (c) 1992 by World Scientific Publishing Co. Pte. Ltd.

All rights reserved. This book, or parts thereof, may not be reproduced in any form or by any means, electronic or mechanical, including photocopying, recording or any information storage and retrieval system now known or to be invented, without written permission from the Publisher.

ISBN 981-02-1120-1

Printed in Singapore by JBW Printers \& Binders Pte. Ltd. 
The contributions of this volume were presented as invited papers or regular papers at the International Conference on Parallel Image Processing 1991, held in Paris, France, June 17-19, 1991. This publication contains a selection of papers by prominent professionals and experts mainly from France, India, Italy, Japan, and the USA. The contributions can be roughly divided into four parts:

\section{(1) Picture Generation and Recognition}

The first paper "Two Topics Concerning Two-Dimensional Automata Operating in Parallel" by K. Inoue, I. Sakuramoto, M. Sakamoto, and I. Takanami investigates the relationship between the recognition power of two-dimensional alternating finite automata and nondeterministic bottom-up cellular acceptors and their complexity. The next paper "Three-Dimensional Object Pattern Representation by Array Grammars" by P. S. P. Wang introduces a new concept of 3-D universal array grammars for representing 3-D patterns and uses parallelism for generating patterns.

The paper "Recognizable Picture Languages" by D. Giammarresi and A. Restivo introduces the notion of ambiguity for recognizable picture languages and discusses the undecidability of the emptiness problem for ambiguous recognizable picture languages. The next paper "Stochastic Puzzle Grammars"' by R. Siromoney, Abdul Huq, M. Chandrasekaran, and K. G. Subramanian extends the notion of puzzle grammars, introduced by M. Nivat and A. Saoudi, to stochastic puzzle grammars and presents an application to the clustering of syntactic patterns.

The last paper in this section "Learning of Patterns and Picture Languages" by R. Siromoney, K. G. Subramanian, and L. Mathew, deals with the problem of learning arrays of digital pictures.

(2) Parallel Recognition and Parsing Algorithms

The paper "Parallel Recognition of High Dimensional Images" by M. Nivat and A. Saoudi introduces a class of high dimensional image grammars and gives some parallel recognition algorithms for this class of array grammars in terms of Parallel Random Access Machines. The second paper of this section "On Parallel Recognition of Two Classes of 2-D Array Patterns" by A. Saoudi and W. Rytter investigates the parallel complexity for recognizing context-free and regular array sets of arrays. The next paper "Two-Dimensional Uniquely Parsable Isometric Array Grammars" by Y. Yamamoto and K. Morita, introduces the class of uniquely parsable array grammars with a deterministic parallel parsing method.

The paper "A Parallel Algorithm for Analyzing Connected Components in Binary Images"' by F. Chiavetta, V. Di Gesù, and R. Renda, describes a parallel algorithm for the Cylindrical Algebraic Decomposition (CAD) of the 2D-discrete space.

(3) Parallel Architectures and Algorithms

The first paper in this section "Replicated Image Algorithms and Their Analysis on SIMD Machines" by P. J. Narayanan, and L. S. Davis presents replicated data algorithms for digital image convolutions and median filter. The second paper "The 
Depth and Motion Analysis Machine" by O. Faugeras, R. Deriche, H. Mathieu, N. Ayache, and G. Randall, describes some algorithms for depth and motion analysis and discusses their implementation on the DMA Machine (i.e. Depth Motion Analysis Machine).

The third paper "Image Analysis on Massively Parallel Computers: An Architectural Point of View" by A. Mérigot and B. Zavidovique presents a set of basic operations for image analysis and their implementation on massively parallel architectures. The fourth paper "Stealth Terrain Navigation for Multi-Vehicle Path Planning" by Y. A. Teng, D. DeMenthon, and L. S. Davis proposes a method for solving visibility-based terrain path planning problems using data parallel machines. It discusses also the implementation of the method on a Connection Machine CM2. The paper "Implementation of the Z-Buffer Algorithm on a Reconfigurable Network of Processors' by J.-J. Li, S. Miguet and Y. Robert describes a parallel implementation of the Z-Buffer algorithm on a distributed memory machine.

\section{(4) Neural Networks}

The first paper of this section "Parallel Algorithm for Colour Texture Generation Using the Random Neural Network Model' by V. Atalay and E. Gelenbe introduces a parallel algorithm for the generation of colour textures using the random neural network model. The second paper "Combining Image Processing Operators and Neural Networks in A Face Recognition System"' by P. Flocchini, F. Gardin, G. Mauri, M. P. Pensini, and P. Stofella describes a system based on the neural paradigm for the recognition of faces and discusses the concept of meta-neural net.

This collection of papers has also been published as a special issue of the International Journal of Pattern Recognition and Artificial Intelligence (Vol. 6, No. 2 $\& 3,1992$ ). We wish to thank all the authors for their contributions and the members of the program committee, without which this volume is impossible. We thank all our sponsors for their help: Délégation Génerale pour l'Armement (DRET), Laboratoire d'Informatique Paris-Nord (LIPN), Université Paris-Nord, Laboratoire d'Informatique Théorique (LITP), and PRC Mathématiques et Informatiques.

M. Nivat, A. Saoudi and P. S. P. Wang

Paris, December 1991 


\section{CONTENTS}

Foreword

A. Saoudi, M. Nivat \& P. S. P. Wang

\section{Picture Generation and Recognition}

Two Topics Concerning Two-Dimensional Automata Operating in Parallel

K. Inoue, I. Sakuramoto, M. Sakamoto \& I. Takanami

Three-Dimensional Object Pattern Representation by Array Grammars

P. S. P. Wang

Recognizable Picture Languages

D. Giammarresi \& A. Restivo

Stochastic Puzzle Grammars

R. Siromoney, A. Huq, M. Chandrasekaran \& K. G. Subramanian

Learning of Pattern and Picture Languages

R. Siromoney, K. G. Subramanian \& L. Mathew

\section{Parallel Recognition and Parsing Algorithms}

Parallel Recognition of High Dimensional Images

M. Nivat \& A. Saoudi

On Parallel Recognition of Two Classes of 2-D Array Patterns

W. Rytter \& A. Saoudi

Two-Dimensional Uniquely Parsable Isometric Array Grammars

Y. Yamamoto \& K. Morita

A Parallel Algorithm for Analyzing Connected Components in Binary Images F. Chiavetta, V. Di Gesù \& R. Renda

\section{Parallel Architectures and Algorithms}

Replicated Image Algorithms and Their Analyses on SIMD Machines P. J. Narayanan \& L. S. Davis

The Depth and Motion Analysis Machine

O. D. Faugeras, R. Deriche, H. Mathieu, N. Ayache \& G. Randall

* Please note that page numbers listed here refer to those at the bottom of each page in the book. 
Image Analysis on Massively Parallel Computers: An Architectural Point of View

A. Mérigot \& B. Zavidovique

Stealth Terrain Navigation for Multi-Vehicle Path Planning

Y. A. Teng, D. DeMenthon \& L. S. Davis

Implementation of the Z-Buffer Algorithm on a Reconfigurable Network of Processors

J.-J. Li, S. Miguet \& Y. Robert

\section{Neural Networks}

Parallel Algorithm for Colour Texture Generation Using the Random Neural Network Model

V. Atalay \& E. Gelenbe

Combining Image Processing Operators and Neural Networks in a Face Recognition System

P. Flocchini, F. Gardin, G. Mauri, M. P. Pensini \& P. Stofella 